\title{
Synthesis and Characterization of Molecularly Imprinted Polymer for Prasugrel Drug Base on 2-Hydroxyethyl Methacrylate Monomer in Biological and Pharmaceutical Samples
}

\author{
Maryam Pyambri Pramani
}

\begin{abstract}
In this research work, a molecularly imprinted polymer (MIP) was synthesized for Prasugrel. In this method, a polymer was first synthesized using 2-hydroxyethyl methacrylate (HEMA) as a monomer, $\mathbf{N}$, N'-methylenebisacrylamide as a crosslinker, and azobisisobutyronitrile (AIBN) as an initiator. The successful synthesis of the MIP was confirmed by elemental analysis (CHN), Fourier-transform infrared (FT-IR) spectroscopy and scanning electron microscopy (SEM). Then, the effects of various parameters such as $\mathrm{pH}$, temperature, MIP capacity, selectivity, adsorption kinetics and adsorption isotherms were investigated by UV-Vis spectroscopy. The calibration curve was plotted for Prasugrel in these conditions and linear range, limit of detection (LOD) and limit of quantification (LOQ) were reported. Finally, the performance of the synthesized MIP as an adsorbent was studied under optimized conditions for the extraction and determination of Prasugrel in tablet matrix and biological fluids such as urine and plasma by high performance liquid chromatography (HPLC).
\end{abstract}

Index Terms-Prasugrel, molecular imprinting polymer, biological fluids, pharmaceutical sample.

\section{INTRODUCTION}

Prasugrel (chemical formula: $\mathrm{C}_{20} \mathrm{H}_{20} \mathrm{FNO} 3 \mathrm{~S}$; molecular weight: 273.442 g.mol ${ }^{-1}$ ) is a white powder that easily dissolves in methanol. It is a prodrug that must be converted to an active metabolite by the liver, and is rapidly transformed into an inactive thiolactone by hydrolases, and then into an active metabolite by CYP enzymes. Prasugrel is bound to proteins (by about 98 percent) and excreted in the urine $(68 \%)$ and feces $(27 \%)$. It is prescribed for patients with hypertension or heart failure in which blood is not pumped sufficiently to the body. Physical and chemical methods such as high performance liquid chromatography (HPLC) and UV spectrophotometry have been reported for detecting and measuring Prasugrel in biological fluids, and thin-layer chromatography (TLC) for drug, plasma, and urine samples. Most drugs are isolated and measured using HPLC because it enjoys high precision, polarity, sensitivity, etc [1]-[6]. In this method, sample preparation is very important because it reduces the matrix effect in biological fluids and yields reliable results [7]. Molecularly imprinted polymers (MIPs) are a new group of synthetic materials with specific recognition sites. MIPs are produced in the form of a 3-D

Manuscript received on April 25, 2019; revised on August 15, 2001.

The author is with Maryam Pyambri Pramani, Islamic Azad University, Iran (e-mail: maryampramani@gmail.com). polymeric network with strong crosslinkers in the copolymerization reaction between a functional monomer and a crosslinker in the presence of a template molecule [8], [9]. After the MIPs are produced, the template molecules are removed from the obtained structure as a result of which binding sites are created with the form, size, and functional groups matching those of the template. Various methods are used to produce MIPs. Liquid polymerization has been used in most reports on preparing these polymers because it is a simpler method. The best results in synthesizing MIPs are obtained by using small templates; therefore, Prasugrel was employed as the template in the present research. Monomer selection requires great care so that it can create active and selective sites for the template. We used 2-hydroxyethyl methacrylate as the monomer because the carboxyl group in its structure enables it to withdraw or donate hydrogen ions in response to $\mathrm{pH}$ changes in the environment and, therefore, can be considered $\mathrm{pH}$ sensitive.

We intended to produce a highly selective and $\mathrm{pH}$ sensitive polymer, and combine MIP-based solid phase extraction (SPE) and HPLC to detect and measure Prasugrel in biological fluids and drug samples.

\section{EXPERIMENTS}

\section{A. Instruments}

IR spectra were recorded on an IR Fourier transform spectrometer (FT-IR-4100, made by Jasco Inc., Easton, Maryland, USA), thermal gravimetric analysis (TGA) was performed employing a thermal analyzer (manufactured by the Shimadzu Corp. in Japan), a scanning electron microscope or SEM (Philips XL-30 FEG-SEM) was used for SEM analysis, elemental analysis by a CHN analyzer (made by the Lineis Messgerate $\mathrm{GmbH}$ Company in Hanau, Germany, Vario El), and UV/Vis spectroscopy by a UV/Vis spectrophotometer (V-530, produced by the Jasco Inc. Easton, Maryland, USA).

\section{B. Reagents and Solutions}

2-hydroxyethyl methacrylate (HEMA) and $\mathrm{N}, \mathrm{N}^{\prime}$ methylenebisacrylamide, hexadecane, acetonitrile, methanol, dipotassium phosphate, and phosphoric acid were bought from the Merck Company (Darmstadt, Germany), azobisisobutyronitrile (AIBN) from the Across Company (New Jersey, USA), and sodium dodecyl sulfate (SDS) from the Fluka Chemical Corp. (Buchs, Switzerland). 
All reagents were HPLC grade. The stock solution (100 mg $\mathrm{L}^{-1}$ ) was prepared by dissolving $5 \mathrm{mg}$ of Prasugrel in $50 \mathrm{ml}$ of methanol, and the $\mathrm{pH}$ of the solution was adjusted using $0.01 \mathrm{M} \mathrm{NaOH}$ or $0.01 \mathrm{M}$ hydrochloric acid.

\section{Polymer Synthesis}

\section{1) MIP preparation}

We needed an organic and an aqueous phase to produce the MIP. To prepare the organic phase, $0.05 \mathrm{~g}$ of $\mathrm{N}, \mathrm{N}^{\prime}-$ methylenebisacrylamide (the crosslinker), $5 \mathrm{ml}$ of HEMA (the monomer), $0.2 \mathrm{~g}$ of hexadecane, $0.01 \mathrm{~g}$ of AIBN (the initiator), and $0.02 \mathrm{~g}$ of Prasugrel were poured into an Erlenmeyer flask and put in an ultrasonic bath for 30 minutes [10]. Thirty $\mathrm{ml}$ of distilled water and $0.015 \mathrm{~g}$ of SDS were used to prepare the aqueous phase. The aqueous phase was added to the organic phase, and placed in a nitrogen atmosphere at $85^{\circ} \mathrm{C}$ for 40 minutes. At the completion of the polymerization process, the resulting white polymer was immediately filtered, washed with $50 \mathrm{ml}$ of methanol, and dried in an oven at $60^{\circ} \mathrm{C}$. The non-imprinted polymer (NIP) was prepared in the same way but without using the template (Prasugrel). FT-IR spectra were obtained for the resulting polymers, and elemental analysis, TGA, and SEM analysis were performed on them.

\section{2) Washing procedure}

The polymer was ground using a mortar and pestle and passed through a $50 \mathrm{~nm}$ filter paper. It was then washed and ultrasonicated in $50 \mathrm{ml}$ of methanol for 30 minutes. This process was repeated four times. Finally, the adsorbent was dried in an oven at $60^{\circ} \mathrm{C}$ and kept at ambient temperature.

\section{3) Isotherm studies}

One $\mathrm{ml}$ of the diluted Prasugrel solution $\left(2.80 \mathrm{mg} \mathrm{L}^{-1}\right)$ and $1 \mathrm{ml}$ of the optimum $\mathrm{pH}$ were added to each $1.5 \mathrm{ml}$ microtube containing $0.01 \mathrm{~g}$ of the adsorbent. The microtubes were then vortexed at $25^{\circ} \mathrm{C}$ for 20 minutes, centrifuged, and the final concentration of Prasugrel in the supernatant was determined using the UV-Vis spectrophotometer. The quantity of Prasugrel in the $q_{e}\left(\mathrm{mg} \mathrm{g}^{-1}\right)$ equilibrium adsorption capacity on the polymer was calculated from the following equation:

$$
q_{e}=\left(C_{0}-C_{e}\right) V / W
$$

In the equation above, $C_{0}$ and $C_{c}\left(\mathrm{mg} \mathrm{L}^{-1}\right)$ are the initial Prasugrel concentration and its concentration after reaching the equilibrium state, $V(\mathrm{~L})$ volume, and $W(\mathrm{~g})$ mass of the employed adsorbent.

\section{4) HPLC system}

An HPLC instrument was used to analyze Prasugrel. Chromatographic separation was performed on a $\mathrm{C}_{18}$ (4.6mm-250mm) column. The mobile phase was a mixture of acetonitrile and phosphate buffer $(600-400 \mathrm{~V} / \mathrm{V})$ at $\mathrm{pH} 3$ with flow rate of $1 \mathrm{ml} \mathrm{min}^{-1}$ in isocratic elution mode. The injection volume of $20 \mu \mathrm{l}$, the wavelength of $210 \mathrm{~nm}$, and the ambient temperature were the same for all samples [11]-[15].

\section{Real Sample}

Blood plasma, urine samples (from a volunteer who was not taking Prasugrel), and real drug (pill) samples were used to evaluate performance of the synthesized polymer in adsorbing and recovering Prasugrel, and $100 \mu \mathrm{l}$ of the Prasugrel stock solution in methanol of HPLC grade was poured in a $50 \mathrm{ml}$ volumetric flask. Solutions containing 100 $\mu \mathrm{l}$ of the drug in the plasma, urine, and actual pill samples were then prepared. For this purpose, $100 \mu \mathrm{l}$ of the stock solution was transferred to a $10 \mathrm{ml}$ volumetric flask. After adding $1 \mathrm{ml}$ of the optimum buffer, the volume was raised to the desired level by addition of plasma. $1.5 \mathrm{ml}$ of these solutions was transferred to each of the $2 \mathrm{ml}$ microtubes containing $0.05 \mathrm{~g}$ of the synthesized polymer. The microtubes were vortexed for 15 minutes and centrifuged for five minutes. The transparent supernatant was separated. 1.5 $\mathrm{ml}$ of the mobile phase was added to the remaining polymer, the mixture was vortexed for 15 minutes, put in an ultrasonic bath for 15 minutes, and centrifuged for five minutes. The supernatant was separated and measurements were made using the HPLC instrument. This was repeated three times, and the average and the relative standard deviation were calculated.

\section{RESULTS AND DISCUSSION}

\section{A. Characterization}

FT-IR spectra were taken and elemental analysis, TGA, and SEM analysis were performed to study the polymer that was molecularly imprinted using the polymerization method with Prasugrel as the template. Data obtained from FT-IR spectra and from CHN analysis is presented in Table I. This table shows the main FT-IR peaks. The band at $299 \mathrm{~cm}^{-1}$ is that of the aliphatic $\mathrm{CH}$ bond in the main structure of the polymer. The data obtained from $\mathrm{CHN}$ analysis shows that there was one crosslinker for every six monomers.

Polymer morphology was studied using the SEM. The SEM images in Fig. 1 show that the synthesized polymeric adsorbent was in the form of agglomerated particles the surfaces of which were rough highly porous. The particle sizes were in the range of about 20-60 nm.

In TGA, the polymer was stable at up to about $230^{\circ} \mathrm{C}$, and had the weight loss of about 3.2 percent at up to $100^{\circ} \mathrm{C}$ (Fig. 2) due to the adsorbed water. At about $240^{\circ} \mathrm{C}$, the polymer skeleton burned and weight loss began.

TABLE I: FOURIER TRANSFORMATION-INFRARED AND ELEMENTAL ANALYSIS INFORMATION

\begin{tabular}{|c|c|c|c|c|c|}
\hline $\begin{array}{l}\text { FT-IR } \\
\text { spectra }\end{array}$ & & & & & \\
\hline \multirow{3}{*}{$\begin{array}{l}\text { Elemental } \\
\text { analysis }\end{array}$} & $\begin{array}{l}3675 \\
\mathrm{~cm}^{-1} \\
\mathrm{O}-\mathrm{H} \\
\text { stretchi } \\
\mathrm{ng}\end{array}$ & $\begin{array}{l}2992 \mathrm{~cm}^{-1} \\
\text { Aliphatic } \\
\mathrm{CH} \\
\text { stretching }\end{array}$ & $\begin{array}{l}1731 \\
\mathrm{~cm}^{-1} \\
\mathrm{C}=\mathrm{O} \\
\text { stretch } \\
\text { ing }\end{array}$ & $\begin{array}{l}1492 \\
\mathrm{~cm}^{-1} \\
\mathrm{CH}_{2} \\
\text { stretc } \\
\text { hing }\end{array}$ & $\begin{array}{l}1068 \\
\mathrm{~cm}^{-1} \\
\mathrm{C}-\mathrm{O} \\
\text { stretchi } \\
\mathrm{ng}\end{array}$ \\
\hline & $\begin{array}{l}\text { Carbon } \\
(\%)\end{array}$ & $\begin{array}{l}\text { Nitrogen } \\
(\%)\end{array}$ & $\begin{array}{l}\text { Oxyge } \\
\mathrm{n}(\%)\end{array}$ & & \\
\hline & 51 & 2.89 & 50.32 & & \\
\hline
\end{tabular}

\section{B. Optimization of Conditions}

To determine the optimum amount of the $\mathrm{N}, \mathrm{N}^{\prime}$. methylenebisacrylamide crosslinker, various amounts of it 
(0.03-0.18) were used in synthesizing the polymer. For this purpose, $0.01 \mathrm{~g}$ of each produced adsorbent together with 1 $\mathrm{ml}$ of the stock solution and $1 \mathrm{ml}$ of the optimum $\mathrm{pH}$ were poured into each microtube, the microtubes were shaken on the vortex for 20 minutes, and the UV-Vis spectrophotometer was employed for quantification. As shown in Fig. 4, the adsorbent synthesized had the highest capacity when $0.15 \mathrm{~g}$ of the crosslinker was used; i.e., it adsorbed the largest amount of the drug in Fig. 3

The quantities of adsorbed Prasugrel were measured at different $\mathrm{pH}$ values. The synthesized polymer is $\mathrm{pH}$ sensitive. Fig. 5 shows that the largest amount of the drug was adsorbed at $\mathrm{pH}$ 6. This was because at lower $\mathrm{pH}$ values the polymer chain was wrinkled and had low adsorption capacity, whereas the ring system of the polymer chain was opened at higher $\mathrm{pH}$ values and the polymer had higher adsorption capacities [16]-[18]. Therefore, $\mathrm{pH} 6$ was considered the optimum $\mathrm{pH}$. The point of zero charge (PZC) was also studied. PZC is the $\mathrm{pH}$ value at which the net charge of the adsorbent is zero. As shown in Fig. 4, pH 6 was the PZC for the synthesized adsorbent. The adsorbent had a positive charge at lower $\mathrm{pH}$ values and a negative charge at higher $\mathrm{pH}$ values.

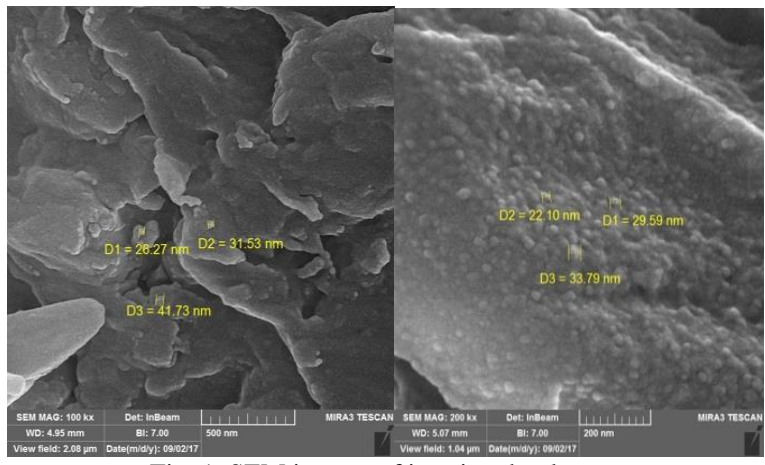

Fig. 1. SEM images of imprinted polymer.

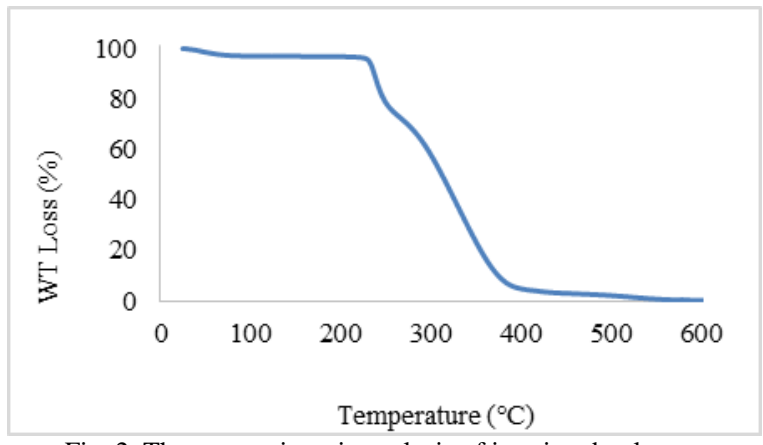

Fig. 2. Thermogravimetric analysis of imprinted polymer.

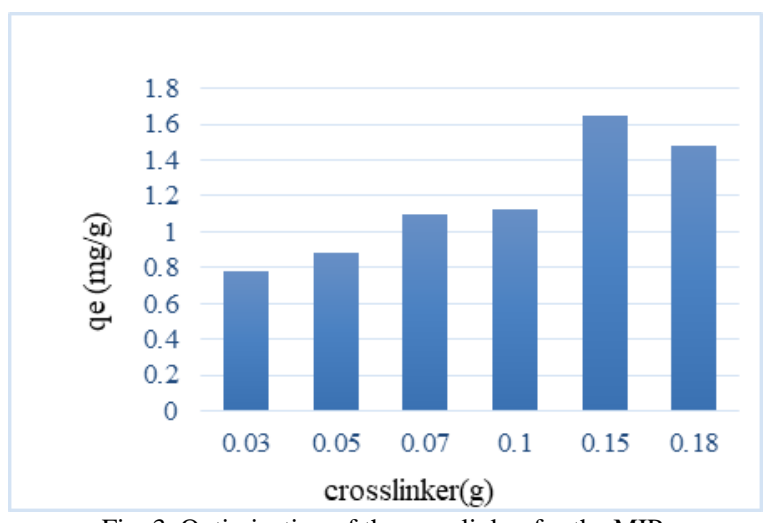

Fig. 3. Optimization of the crosslinker for the MIP.
Prasugrel adsorption as a function of time at $\mathrm{pH} 6$ is shown in Fig. 6. It was found that 15 minutes was enough for more than 96 percent of Prasugrel to be adsorbed. This indicates that the adsorption sites on the polymer were activated and enjoyed good accessibility.

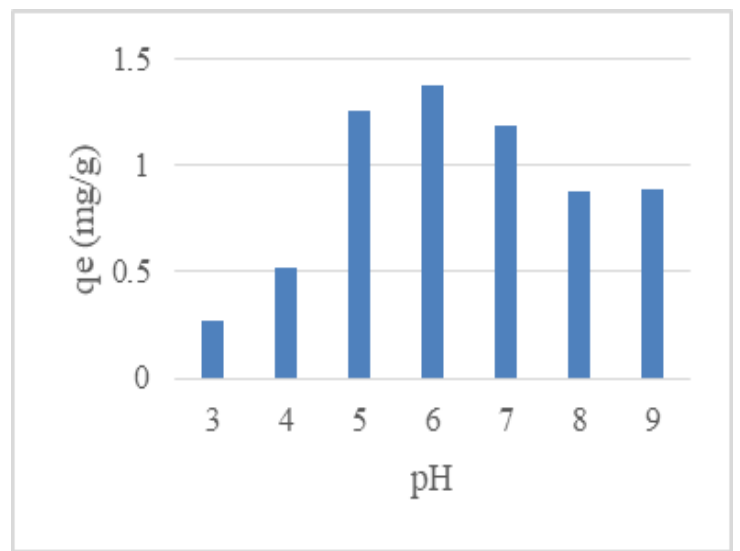

Fig. 4. Effects of $\mathrm{pH}$ value on Prasugrel adsorption by the synthesized polymer. Each $10 \mathrm{ml}$ contained $20 \mathrm{mg} \mathrm{L}^{-1}$ of Prasugrel. Buffer solutions (Magic Buffer) were used to adjust the $\mathrm{pH}$. The synthesized adsorbent $(0.01$ g) was added to each solution and the solution was shaken with a vortex mixer for 20 minutes.

Moreover, the synthesized polymer was studied at different temperatures. As shown in Fig. 7, adsorption decreased at higher temperatures. Mobility declined at low temperatures resulting in reduced adsorption. We can say that the synthesized adsorbent had suitable efficiency at various temperatures and temperature did not influence its adsorption capacity.

\section{Isotherm Studies}

Langmuir, Freundlich, and Temkin isotherms were employed to study Prasugrel adsorption by the synthesized polymer at ambient temperature. Equations 1-3 were used to obtain adsorption parameters. Results are listed in Table II [19]-[21].

$$
\begin{gathered}
\text { Langmuir equation: } C_{e} / q_{e}=\left(1 / q_{\operatorname{Max}} K_{L}\right)+\left(C_{e} / q_{\operatorname{Max}}\right) \\
\text { Freundlich equation: } \ln q_{e}=\ln K_{F}+1 / \ln C_{e} . \\
\text { Temkin equation: } q_{e}=\mathrm{B} \ln \mathrm{A}+\mathrm{B} \ln C_{e}
\end{gathered}
$$

In Table II, $q_{\text {Max }}$ represents the highest adsorption capacity of a full layer on the adsorbent surface $\left(\mathrm{mg} \mathrm{g}^{-1}\right), K_{L}$ Langmuir constant $\left(\mathrm{L} \mathrm{mg}^{-1}\right), R_{L}$ the Langmuir dimensionless constant separation factor, $K_{F}$ the Freundlich constant $\left(\mathrm{mg} \mathrm{g}^{-1}\right)(\mathrm{L}$ $\left.\mathrm{mg}^{-1}\right), 1 / \mathrm{n}$ the heterogeneity factor, B the constant related to the heat of adsorption and defined by the expression $\mathrm{B}=\mathrm{RT} / \mathrm{b}$ (where $\mathrm{b}$ is the Temkin constant $\left(\mathrm{J} \mathrm{mol}^{-1}\right)$, A the Temkin constant $\left(\mathrm{L} \mathrm{g}^{-1}\right), \mathrm{R}$ the gas constant $\left(8.314 \mathrm{~J} \mathrm{~mol}^{-1} \mathrm{~K}^{-1}\right)$, and $\mathrm{T}$ the absolute temperature $(\mathrm{K})$.

Langmuir adsorption isotherm, one of the most widely used adsorption isotherms, was used to determine adsorption capacity (the amount of Prasugrel adsorbed by $1 \mathrm{~g}$ of the adsorbent). The values of adsorption capacity at equilibrium $\left(q_{e}\right)$ were plotted against $C_{e}$, and the $C_{e} / q_{e}$ curve indicated a linear relationship. The Langmuir constant $\left(q_{M a x}\right)$ and $K_{L}$ can be calculated from the slope and y-intercept of the curve. The value of $R_{L}$ at $\mathrm{pH}$ was 0.02 (Table II), which suggests that Prasugrel uptake was at a desirable level. 
TABLE II: ISOTHERM PARAMETERS OBTAINED BY USING LINEAR METHOD

\begin{tabular}{lllll}
\hline \hline Langmuir & & & & \\
\hline & $\begin{array}{l}\mathrm{q}_{\mathrm{Max}} \\
\left(\mathrm{mg} \cdot \mathrm{g}^{-1}\right)\end{array}$ & $\begin{array}{l}\mathrm{K}_{\mathrm{L}} \\
(\mathrm{L} \cdot \mathrm{mg})\end{array}$ & $\mathrm{R}_{\mathrm{L}}$ & $\mathrm{R}^{2}$ \\
Freundlich & 1.54 & 0.48 & 0.02 & 0.9974 \\
& $\begin{array}{l}\mathrm{K}_{\mathrm{F}} \\
(\mathrm{mg} \cdot \mathrm{g})\left(\mathrm{L} \cdot \mathrm{mg}^{-1}\right.\end{array}$ & $\mathrm{n}$ & $\mathrm{R}^{2}$ & \\
& ) & 3.47 & 0.97824 & \\
Temkin & 0.54 & $\mathrm{~B}$ & $\mathrm{~b}$ & $\mathrm{R}^{2}$ \\
& $\mathrm{~A}\left(\mathrm{~L} \cdot \mathrm{g}^{-1}\right)$ & $\left.\mathrm{B} \cdot \mathrm{mol}^{-1}\right)$ & \\
& 19.68 & 0.217 & 10459.5 & 0.9742 \\
\hline \hline
\end{tabular}

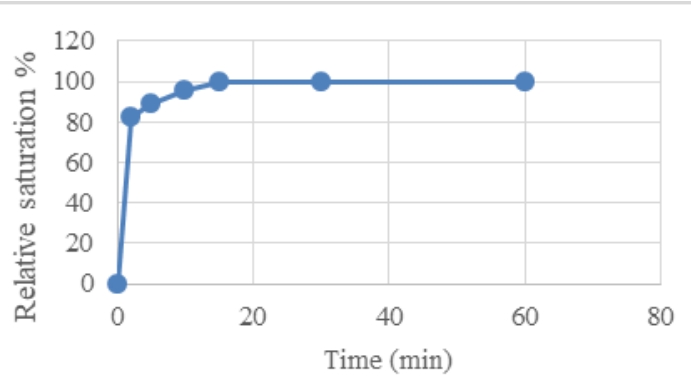

Fig. 5. Presents the kinetics of Prasugrel adsorption on the MIP. Each $10 \mathrm{ml}$ contained $20 \mathrm{mg} \mathrm{L}^{-1}$ of Prasugrel. The MIP $(0.01 \mathrm{~g})$ was added to each solution and the solution was shaken with a vortex mixer for different durations at $\mathrm{pH} 6$.

Freundlich adsorption isotherm indicates the relationship between the amounts of the drug adsorbed for every mass unit of the adsorbent $q_{e}$ and shows Prasugrel concentration in the solution in the $C_{e}$ equilibrium state. The diagram of $\ln q_{e}$ $\left(\mathrm{mg} \mathrm{g}^{-1}\right)$ against $C_{e}\left(\mathrm{mg} \mathrm{L}^{-1}\right)$ was drawn. The Freundlich adsorption isotherm suggested that Prasugrel concentration on the adsorbent improved as long as its concentration in the solution increased.

The Temkin equation demonstrates that sorption energy declines linearly on completion of the sorption centers of an adsorbent. Plotting $q_{e}$ against $\ln C_{e}$ helps in determining the $\mathrm{A}$ and B constants. Results are presented in Table II.

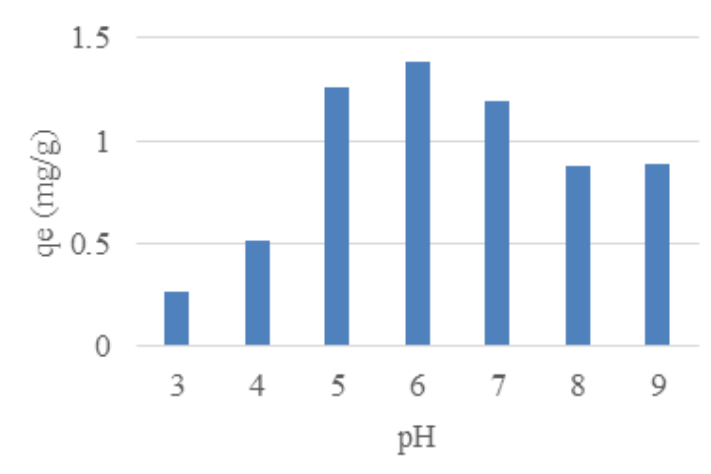

Fig. 6. Shows the effects of the adsorbent on temperature. Each $10 \mathrm{ml}$ contained $20 \mathrm{mg} \mathrm{L}^{-1}$ of Prasugrel. The MIP $(0.01 \mathrm{~g})$ was added to each solution, and the mixture was shaken with a vortex mixer at various temperatures at $\mathrm{pH} 6$.

\section{Selectivity of the Sorbent}

The quantities of Prasugrel adsorbed on the NIP and MIP were studied and compared. The equation for the selectivity coefficient $\beta$, which is used to investigate bonds in MIPs, is as follows [22] :

$$
\beta=Q_{\text {(imprinted })} / Q_{(\text {non-imprinted })}
$$

TABLE III: SIGNIFICANT PARAMETER FOR SELECTIVITY OF PRASUGREL

\begin{tabular}{lll}
\hline \hline & MIP & NIP \\
\hline$\beta$ & 1.32 & \\
$\mathrm{DC}_{\text {Prasugrel }}$ & 3.19 & \\
$\mathrm{DC}_{\text {Clonazepam }}$ & 0.67 & \\
$\mathrm{~K}_{\text {Prasugrel/Clonazepam }}^{\prime}$ & 4.76 & 0.18 \\
$\mathrm{~K}^{\prime \prime}$ Prasugrel/Clonazepam & 26.44 & \\
\hline \hline
\end{tabular}

In the equation above, $Q_{\text {(imprinted) }}$ represents the capacity of Prasugrel for bond formation in the MIP $\left(\mathrm{mg} \mathrm{g}^{-1}\right)$ and $Q$ (non-imprinted) the capacity of Prasugrel for bond formation in the NIP $\left(\mathrm{mg} \mathrm{g}^{-1}\right)$. Table III illustrates that the selectivity coefficient for the synthesized polymer was 1.32. In fact, we can say that the MIP cavities create specific sites in the MIP networks that selectively adsorb Prasugrel, whereas the NIP lacks these MIP sites and has a lower capacity for Prasugrel-binding. The drug Clonazepam was also employed to study and compare adsorption by MIP and NIP.

Distribution coefficients (DCs) of the selected substrates between the solution and the polymer were calculated using the following equation:

$$
\mathrm{DC}=C_{p} / C_{s}
$$

In the equation above, $\mathrm{C}_{\mathrm{p}}$ and $\mathrm{C}_{\mathrm{s}}$ are the concentrations of the substrates in the polymer and in the solution, respectively. Higher calculated value of DC for Prasugrel compared to Clonazepam suggests that the MIP was able to create special sites that were able to recognize the best molecule for the MIP cavity. Results are presented in Table III. Furthermore, the selectivity coefficient of the adsorbent $K^{\prime}$ (which represents the two materials adsorbed by one adsorbent) and the relative selectivity coefficient $K^{\prime \prime}$ (which stands for the difference between the two adsorbents) were studied and calculated using the following equations [23]:

$$
K^{\prime}=\mathrm{DC}_{\mathrm{A}} / \mathrm{DC}_{\mathrm{B}}
$$

In the equation above, DCA and DCB represent template distribution coefficients and distribution coefficients of other materials adsorbed by the adsorbent, respectively [24]-[25].

$$
\underline{\mathrm{K}^{\prime \prime}}=K_{\text {imprinted }}^{\prime} / K_{\text {non-imprinted }}^{\prime}
$$

The higher value of $K^{\prime}$ for the MIP compared to the NIPs indicates that the MIP had higher selectivity for Prasugrel.

\section{E. Application of the Method}

Drug extraction from urine, plasma, and drug samples Fig. 8 was carried out to see whether the method proposed for Prasugrel determination was suitable for real samples. Extraction was performed under optimal conditions using the method presented in this article. Results are listed in Table IV. 
Extraction was performed under optimal conditions for human plasma and urine. The separately controlled extracted samples were negative for HBS antigen, hepatitis C antibodies, and HIV I and II. Results in Table IV indicate that this method is suitable for measuring amounts of Prasugrel in urine samples. The reason for the low recovery of the drug in plasma samples is that the proteins in these samples occupy the existing sites on the adsorbent. We can say that the method introduced in this article enjoys good precision.

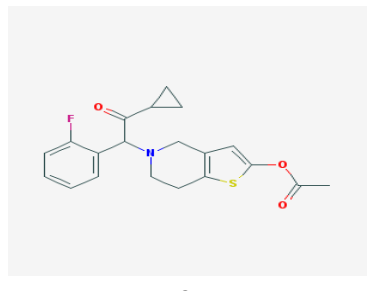

a

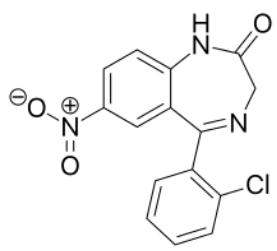

b
Fig. 8. Chemical structures of studied compound: (a) Prasugrel (b) Clonazepam.

\section{F. Analytical Performance of the Proposed Method}

Table V presents the linear relationship and selectivity of this method for the drug Prasugrel. The calibration curve was drawn using the standards at various concentrations under optimal conditions. The following equations were employed to calculate the limit of detection (LOD) and the limit of quantification (LOC) for the drug of interest:

$$
\begin{gathered}
\mathrm{LOD}=3 \sigma / \mathrm{m} \\
\mathrm{LOQ}=10 \sigma / \mathrm{m}
\end{gathered}
$$

In the equations above, $\sigma$ is the standard deviation $(\mathrm{SD}, \mathrm{n}=6)$ and $\mathrm{m}$ the slope of the calibration curve. As results in Table $\mathrm{V}$ indicate, the $R^{2}$ value $(0.9774)$ and the values for LOD and LOQ are relatively good. Therefore we can conclude that the analytical performance of the proposed method was good.

TABLE IV: DETERMINATION OF PRASUGREL IN DIFFERENT SAMPLES.

\begin{tabular}{llllll}
\hline \hline Samples & $\begin{array}{l}\text { Concentra } \\
\text { tion of } \\
\text { Prasugrel } \\
\left(\mu \mathrm{g} . \mathrm{mL}^{-1}\right)\end{array}$ & $\begin{array}{l}\text { Adde } \\
\mathrm{d} \\
(\mu \mathrm{g} .\end{array}$ & $\begin{array}{l}\text { Found } \\
(\mu \mathrm{g} . \mathrm{m})\end{array}$ & $\begin{array}{l}\left.\mathrm{L}^{-1}\right) \\
\text { Recove } \\
(\%)\end{array}$ & $\begin{array}{l}\text { RSD } \\
(\%)\end{array}$ \\
\hline Drug & 1.00 & & 1.02 & 102 & 5.85 \\
Urine & & 1.00 & 0.89 & 89 & 1.86 \\
Plasma & & 1.00 & 0.28 & 28 & 13.58 \\
\hline \hline
\end{tabular}

TABLE V: ANALYTICAL PERFORMANCE OF PRASUGREL

\begin{tabular}{ll}
\hline \hline Analytical calibration curve & $\mathrm{Y}=0.0128 \mathrm{X}+0.0034$ \\
\hline $\mathrm{R}^{2}$ & 0.9774 \\
$\begin{array}{l}\text { Liner range } \\
\left(\mu \mathrm{g} . \mathrm{mL}^{-1}\right)\end{array}$ & $0.1-50$ \\
$\begin{array}{l}\text { RSD } \\
\text { Repeatability }\end{array}$ & 0.86 \\
$\begin{array}{l}\text { Reproducibility } \\
\text { LOD } \\
\left(\mu \mathrm{g} . \mathrm{L}^{-1}\right)\end{array}$ & 0.97 \\
$\begin{array}{l}\mathrm{LOQ} \\
\left(\mu \mathrm{g} . \mathrm{L}^{-1}\right)\end{array}$ & 0.09 \\
\hline \hline
\end{tabular}

\section{CONCLUSIONS}

The synthesized MIP is $\mathrm{pH}$ sensitive and releases the adsorbed drug at $\mathrm{pH}$ 6. Moreover, we can say the synthesized MIP has high selectivity for Prasugrel and can be reused for up to four times. Results obtained for Prasugrel extraction by the MIP reported $89 \%$ recovery for the urine samples and $28 \%$ for the plasma samples. This suggests that the synthesized MIP can be used in analytical studies.

\section{ACKNOWLEDGMENT}

Sincerely thank Mr. Homayon Ahmad Panahi for his guidance and encouragement in carrying out this project work.

\section{REFERENCES}

[1] W. L. Baker and C. M. White, "Role of Prasugrel, a novel P2Y12 receptor antagonist, in the management of acute coronary syndromes," American Journal of Cardiovascular Drugs, vol. 9, no. 4, pp. 213-229, 2009.

[2] S. D. Wiviott, E. Braunwald, and C. H. McCabe, "Prasugrel versus Clopidogrel in patients with acute coronary syndromes," N. Engl. J. Med., vol. 357, no. 20, pp. 2001-2015, 2007.

[3] Food and Drug Administration (United States), FDA Announces New Boxed Warning on Plavix: Alerts Patients, Health Care Professionals to Potential for Reduced Effectiveness, Press Release, March 13, 2010.

[4] FDA Drug Safety Communication: Reduced Effectiveness of Plavix (clopidogrel) in Patients Who Are Poor Metabolizers of the Drug, Drug Safety and Availability, Food and Drug Administration (United States), March 12, 2010.

[5] D. J. Angiolillo, J. F. Saucedo, and R. DeRaad, "Increased platelet inhibition after switching from maintenance Clopidogrel to prasugrel in patients with acute coronary syndromes," J. Am. CollCardiol., vol. 56, pp. 1017-1023, 2010.

[6] M. O'Riordan. ( 2011). Switching from clopidogrel to prasugrel further reduces platelet function. [Online]. Available: http://www.theheart.org

[7] V. Pichon and F. Chapuis-Hugon, "Role of molecularly imprinted polymers for selective determination of environmental pollutants - A review," Anal. Chim. Acta, vol. 622, no. 1-2, pp. 48-61, 2008.

[8] D. Wang, S. Pyo Hong, G. Yang, and K. Ho, "Caffeine molecular imprinted microgel spheres by precipitation polymerization," Korean J. Chem. Eng., vol. 20, no. 6, pp. 1073-1076, 2003.

[9] I. Dakova, I. Karadjova, V. Georgieva, and G. Georgiev, "Ion-imprinted polymethacrylic microbeads as new sorbent for preconcentration and speciation of mercury," Talanta, vol. 78, no. 2, pp. 523-529, 2009.

[10] H. A. Panahi, J. Morshedian, N. Mehmandost, E. Moniri, and I. Y. Galaev, "Grafting of poly [1-(N,N-bis-carboxymethyl) amino-3-allylglycerol-co-dimethylacrylamide] copolymer onto siliceous support for preconcentration and determination of lead (II) in human plasma and environmental samples," J. Chromatogr. A., vol. 1217, no. 32, pp. 5165-5172, 2010.

[11] R. K. Rajendiran, V. K. Sekar, B. D. Namadevan, J. K. Annamalai, and S. Devarajan, "UV-spectrophotometric and RP-HPLC methods for the estimation of prasugrel hydrochloride in bulk and tablet formulation," Int. J Pharm. Pharm. Sci., vol. 6, no. 1, pp. 220-225, 2014.

[12] S. D. Darshali, S. B. Bharati, and G. W. Sanjay, "Stability indicating method for quantitation of prasugrel hydrochloride in presence of its degradation products," International Journal of Pharmacy \& Technology, vol. 4, no. 3, pp. 4711-4720, 2012.

[13] R. W. Enaksha, T. Ye, J. R. Kenneth, M. V. Elizabeth, J. W. Govinda, K. Atsushi, A. F. Nagy, "Stereo selective metabolism of prasugrel in humans using a novel chiral liquid chromatography-tandem mass spectrometry method," Drug Metabolism and Disposition, vol. 35, no. 6, pp. 917-921, 2007.

[14] T. C. Borole, R. Mehendre, M. C. Damle, and K. G. Bothara, "Development and validation of stability indicating HPTLC method for determination of Prasugrel," J. Chem. Pharm. Res., vol. 2, no. 4, pp. 907-913, 2010.

[15] I. Srikanth, P. Sharmila, K. Vijayabharathi, M. Raju, M. LakshmaNaik, and K. Nagarjuna, "A validated reverse phase HPLC method for the estimation of prasugrel hydrochloride in pharmaceutical dosage forms," JITPS, vol. 2, no. 5, pp. 140-148, 2011.

[16] C. Baggiani, C. Giovannoli, L. Anfossi, and C. Tozzi, "Molecularly imprinted solid-phase extraction sorbent for the clean-up of chlorinated 
phenoxyacids from aqueous samples," J. Chromatogr. A, vol. 938, no.1-2, pp. 35-44, 2001.

[17] G. Theodoridis, A. Kantifes, P. Manesiotis, N. Raikos, and T. P. Heleni, "Preparation of a molecularly imprinted polymer for the solid-phase extraction of scopolamine with hyoscyamine as a dummy template molecule," J. Chromatogr. A, vol. 987, no.1-2, pp. 103-109, 2003.

[18] E. P. C. Lai and S. G. Wu, "Molecularly imprinted solid phase extraction for rapid screening of cephalexin in human plasma and serum," Anal. Chim. Acta, vol. 481, no. 2, pp. 165-174, 2003.

[19] L. Langmuir, J. Am. Chem. Soc.,vol. 40, p. 1361, 1918.

[20] H. M. A. Frendlich, "Over the adsorption in solution," J. Phys. Chem., vol. 57, pp. 385-471, 1906.

[21] M. I. Tempkin and V. Pyzhev, "Kinetics of ammonia synthesis on promoted iron catalyst," Acta Phys Chim USSR, vol. 12, pp. 327-356, 1940.

[22] G. Jin and Y. Tang, "Evaluation of a novel silica-supported sol-gel sorbent prepared by a surface molecular imprinting technique for the selective separation of estazolam from human plasma," Microchim. Acta, vol. 165, p. 143, 2009.

[23] H. Guo and X. He, "Study of the binding characteristics of molecular imprinted polymer selective for cefalexin in aqueous media," Fresenius J. Anal. Chem., vol. 368, pp. 461-465, 2000.
[24] D. M. Han, G. Z. Fang, and X. P. Yan, "Preparation and evaluation of a molecularly imprinted sol-gel material for on-line solid-phase extraction coupled with high performance liquid chromatography for the determination of trace pentachlorophenol in water samples," $J$. Chromatogr. A, vol. 1100, no. 2, pp. 131-136, 2005.

[25] X. Jiang, C. Zhao, N. Jiang, H. Zhang, and M. Liu, "Selective solid-phase extraction using molecular imprinted polymer for the analysis of diethylstilbestrol," Food Chem., vol. 108, no. 3, pp. 1061-1067, 2008.

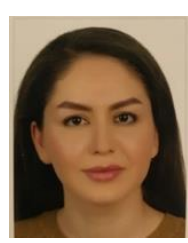

Maryam Pyambri Pramani was born in 18 June, 1991 In 2015-2017, she got the M.Sc in analytical chemistry from Azad University Central Tehran Branch in Tehran, Iran. In 2009-2014, she obtained the B.A. in applied chemistry from Azad University Central Tehran Branch in Tehran, Iran. From 2012 to 2014, she worked in A.R.M Company in Tehran, Iran as a chemical lab supervisor. In 2014-2017, she worked in Asphalt \& Bitumen West Company in Tehran, Iran as a chemical lab supervisor. 